\title{
La DLE: de hoy para mañana
}

\author{
José Manuel Vez \\ Observatorio 'Janua Linguarum' para las LEs \\ ICE de la Universidad de Santiago de Compostela
}

\begin{abstract}
Given the outstanding position that foreign language teaching, foreign language teachers, and foreign language teacher educators have at present under a European perspective, it seemed to me more appropriate to explore several key areas and their interactions rather than focus this paper on a single topic. Many experienced members of the FL profession will concur that the past 25 or more years have seen a fragmentation of research based on individual researchers' agendas, rather than a broad-based, collective one. The overall goal of my contribution to the first issue of Porta Linguarum is to analyse key trends in the mid- and late- 1990s as well as the forthcoming perspectives in both the various teaching situations and research grounds.
\end{abstract}

RESUMEN: Teniendo en cuenta el papel destacado que hoy en día ocupa la didáctica de las lenguas extranjeras, el profesorado de estas lenguas, y los didactas que nos ocupamos de sus problemáticas en la docencia y en la investigación, sobre todo desde una perspectiva europea, me ha parecido más oportuno recurrir a un estudio reflexivo de varios aspectos clave en esta dimensión, así como de sus respectivas interacciones, evitando centrar mi análisis en uno de sus múltiples focos de atención. Muchos de los lectores de este trabajo, como expertos en estas cuestiones, estarán de acuerdo en que los pasados 25 años han sido testigos de una fragmentación de la investigación en DLE que prima los intereses particulares de los propios investigadores en lugar de apoyar la construcción de una amplia base de colaboración en red. Mi principal objetivo con esta contribución a la primera edición de Porta Linguarum no es otro que el de analizar algunos centros clave de interés en el desarrollo de la DLE desde mediados de los años noventa a la luz de las metas que, a mi juicio, deberían centrar el trabajo del área en el futuro tanto en el ámbito docente como investigador.

PALABRAS CLAVE: Didáctica de lenguas extranjeras; formación y desarrollo profesional del profesorado de lenguas extranjeras; marco europeo común de referencia; intercomprensión paneuropea; investigación; nichos ecológicos.

\section{INTRODUCCIÓN}

Hace ya más de dos décadas, en 1980, Robert Galisson publicaba un libro emblemático ${ }^{1}$ que representaba un estudio seminal sobre el tránsito del estructuralismo al funcionalismo en

${ }^{1}$ Me refiero a la obra $D$ 'hier à aujourd hui la didactique générale des langues étrangères. Du structuralisme au fonctionnalisme editado por Clé International en Paris. 
relación a sus aportaciones para la didáctica de las lenguas y culturas extranjeras. Gracias a aquel recorrido, de ayer a hoy, muchos aprendíamos por aquellos años a fortalecer nuestras primeras intuiciones en torno a los problemas de la enseñanza y el aprendizaje de lenguas diferentes a la propia (o propias) ${ }^{2}$, al tiempo que construíamos nuestro conocimiento profesional didáctico de manera más fundamentada. Y es justamente en 1980 cuando, superando dificultades aquí innombrables, se defienden -por vez primera en España- dos Tesis doctorales que centran su objetivo en un aspecto didáctico de la lengua extranjera: la de D. Madrid, en la Universidad de Granada, titulada Estudio experimental sobre la enseñanza del inglés de 6 a 8 años y la mía, en la de Santiago de Compostela, Una aproximación integral-generativa en la enseñanza del Inglés en la $E G B^{3}$ Un poco más tarde, gracias al estudio multidisciplinar de H. H. Stern en $1983^{4}$, los didactas de LEs de nuestro país, al igual que en el resto del mundo, dotábamos de sentido científico a nuestro conocimiento didáctico del contenido.

\section{UN ESPACIO DE BORROSIDAD}

Claro que por aquellos años no existen todavía en la universidad española las áreas de conocimiento científico tal como hoy las conocemos. La creciente y apasionante literatura especializada en Didáctica de las Lenguas Extranjeras (en adelante, DLE) que se va desarrollando a partir de los ochenta no logra evitar, a día de hoy, el desconcierto que vivimos quienes profesamos en esta didáctica específica desde nuestra adscripción universitaria al área de conocimiento Didáctica de la Lengua y la Literatura. El sentido de la cursiva en lo que antecede no es otro que el de llamar la atención del lector no especializado en el contexto universitario español sobre el hecho de que, por extraño que resulte, es posible y, lamentablemente, es una realidad muy extendida, que quienes profesan en áreas de conocimiento que nada tienen que ver con la Didáctica (digamos Filología Inglesa, Filología Francesa, Lengua Española, etc.) dediquen la mayor parte de sus trabajos de divulgación, e incluso sus trabajos de investigación, a cuestiones que, sin resultar en absoluto pertinentes en sus respectivas áreas de adscripción universitaria, obtienen el beneficio del rigor en cuanto a lo que ciertamente aportan a la construcción del conocimiento profesional en el ámbito de las lenguas extranjeras (a partir de aquí, LEs).

\footnotetext{
${ }^{2}$ La alternancia entre la denominación "lenguas extranjeras" y la expresión "lengua distinta a la propia (o propias)" no es estilística; es conceptual. Nadie puede seguir estando hoy de acuerdo en que términos, todavía al uso, del tipo "lenguas extranjeras" "lenguas modernas", "lenguas vivas", etc. tengan algún sentido, por ejemplo, en la dimensión europea - un contexto con el que la DLE en España tiene una deuda pendiente. Aún así, no existe una alternativa que logre un mínimo consenso y se instale, de manera mucho más feliz, en nuestro territorio. Un problema menor al lado de los grandes escollos que debemos salvar los didactas de estas lenguas para acrecentar lo que nos une y reducir lo que nos separa.

${ }^{3}$ Sobre la segunda, cabe destacar el hecho de que su título original comenzaba por "Un enfoque didáctico...". En 1978, ya finalizada y presentada, es rechazada por autoridades competentes del momento bajo el argumento de que la palabra "didáctica" no podía aparecer, en modo alguno, en el título de una Tesis doctoral. Tras 2 años de inútiles reclamaciones formales, claudico y cambio la denominación por una más al gusto de los imperativos filológicos de aquella época.

${ }^{4}$ La obra de referencia es Fundamental Concepts in Language Teaching, editada por OUP.
} 
Y es que, como dejó claro D. Schön (1992: 9-10) hace ya un tiempo, las universidades y la investigación formal que en ellas tiene lugar, a menudo centrada en modelos propios de una racionalidad técnica, acaba originando una dilema entre el rigor y la pertinencia que es bastante difícil de salvar. No cabe duda que ni el contexto francófono en DLE, iluminado muy directamente por la obra de Galisson, ni el contexto anglosajón para el que el excelente trabajo de Stern fue un referente ineludible, tuvieron nunca la dificultad de enfrentarse a la cuestión a que aquí hago referencia. Tal vez encontremos ahí una posible explicación a la inocente confusión a que vengo aludiendo:

- esta forma borrosa de actuar podría tener que ver con la impregnación en modos de pensar y de hacer por analogía con las fuentes internacionales que a uno le proporcionan mayor grado de empatía;

- tal vez las cosas sean mucho más simples y todo se circunscribe al hecho de que unos y otros procedemos del mismo tipo de estudios iniciales, en nuestras respectivas carreras universitarias, y claro, ya se sabe, compañeros de carrera al fin que han principiado su aventura profesional partiendo de la misma senda, luego han seguido rutas diferentes, pero al fin y al cabo, ¿no es cierto?... todos los caminos conducen a Roma.

Claro que, de hecho, con empatía o antipatía, romeros o arrieros en la misma senda, con vaquillas propias o ajenas, la realidad española de la DLE es que ni están todos los que son ni son todos los que están.

No cabe duda que, en la construcción de todo territorio científico, el peso de las tradiciones supone un lastre que no sólo frena el avance en el saber y en el saber hacer de ese territorio, sino que dificulta la clarificación de la identidad que precisa para ser reconocido y admitido. $\mathrm{Si}$, como creo, las tradiciones en DLE, y su peso en la configuración de un espacio de reconocimiento científico, no van mucho más allá de una orientación instrumental, fuertemente condicionada por el reduccionismo a lo metodológico, es absolutamente admisible el hecho de que las miradas que, en un tiempo no lejano, se han dirigido a nuestro campo de actuación desde otras ciencias del lenguaje, desde la psicología educativa, o desde la misma pedagogía (amén de la miradas de soslayo que a unos y otros nos hayan podido corresponder desde la atalaya de los territorios de las ciencias duras), fuesen miradas iluminadas por el rictus de la desconfianza, la incredulidad o el desprecio mismo. Pero las miradas no son eternas, como no lo es el propio conocimiento. Y las del ayer no son las miradas del hoy. Desde luego no pueden ser, no van a ser, las de mañana. No lo están siendo ya.

De hoy para mañana, los avances en el territorio de construcción del rigor y la pertinencia del campo científico de la DLE, habrán disipado la borrosidad de nuestro conocimiento compartido. Tal vez no podamos asegurar, como tanto nos gustaría, que ello es debido al esfuerzo de los didactas del área de conocimiento que nos une. Ni somos tantos, ni es verdad que estemos tan unidos en la construcción de ese conocimiento. Si es así, y si es cierto que los indicios de hoy apuntan a una definición de la DLE en el mañana, es porque tenemos ante nosotros un territorio de crecimiento que, por fuerza, hará de nuestro interés académico un interés social. La actual exigencia de calidad y excelencia que se dibuja en el horizonte del compromiso público en torno a la educación y a la investigación se plantea como una valla más en la carrera de obstáculos que hace pocos años hemos iniciado para poder subir al podio donde las medallas se entregan, de forma exclusiva, a las áreas de conocimiento que han obtenido el reconocimiento científico. 
Y para ello no podemos seguir instalados, de manera cómoda o incómoda, en las tierras bajas del valle donde crecen los juncos en los humedales y se multiplica la correhuela en los caminos. Sin duda, el mapa topográfico de la DLE es muy variopinto... un mapa con cotas y relieves muy semejante al de las propias tierras de nuestro país. Existen unas tierras altas y firmes donde los problemas son fáciles de controlar y se solucionan aplicando teorías y técnicas que tienen como base fundamental la investigación lingüística, pura y dura. En las tierras bajas del valle, los problemas resultan confusos y poco claros... se nos resisten a una solución técnica. En unas y otras tierras, la generosidad abunda y, así, todo aquel que tiene algo que decir sobre un aspecto didáctico de tal o cual lengua encuentra fácilmente dónde divulgarlo, al margen de su ubicación en una determinada área de conocimiento. Porque en estas tierras tolerantes y permeables, a diferencia de las políticas científicas de las ciencias duras, no importa la adscripción al área a la hora de investigar y, menos aún, a la hora de publicar. Y, así, la borrosidad se plantea sin solución de continuidad.

Claro que lo paradójico de esta situación, en un mundo donde las enseñanzas y los aprendizajes de las LEs son formas de vida, de socialización básica, es que los problemas de las tierras altas tienden a ser de relativa o muy escasa importancia para la sociedad en su conjunto -naturalmente, a pesar de lo relevante de su interés técnico para quienes se los plantean- mientras que en las tierras bajas residen aquellos otros problemas de mayor preocupación humana. Averiguar todo lo que es preciso destacar sobre las variantes alofónicas de una africada sorda que producen determinados sujetos de una comunidad de mormones al norte del estado de Utah (y sus aplicaciones didácticas) es de mayor relevancia científica, y de mayor promoción académica, que el calado que pueda tener una investigación sobre las razones que justifican que una lengua extranjera que se plantea como 'asignatura' en el desarrollo curricular de los centros escolares, pueda jamás llegar a ser -para quienes sólo así tienen la posibilidad de apropiarse de ella- un modo de comportamiento ciudadano culto en la creciente sociedad del mestizaje. Claro que lo segundo tiene una relevancia social que no tiene lo primero.

Por otra parte, no debemos pasar por alto el hecho de que el peso de las tradiciones alimenta modos de hacer que repercuten en la cualificación de la borrosidad a que vengo aludiendo. Mientras resulta cada vez más frecuente que quienes investigan sobre problemas relativos a cualquiera de las múltiples facetas de la DLE desde su atalaya de las tierras altas lo hagan como resultado de una tarea en equipo, el quehacer de los adscritos al área de conocimiento que permanece en las tierras del valle no revela que el trabajo de equipo progrese en igual modo. Excepción hecha de los trabajos de colegas de las universidades de Granada, Barcelona, Autónoma de Barcelona, Murcia, Santiago y pocas más, la inmensa mayoría de estas investigaciones forman parte de un esfuerzo individual y escasamente colaborativo. En el marco de una situación universal en la que el desarrollo profesional de cualquier campo del saber y del saber hacer pasa por el trabajo en grandes redes transnacionales...

¿qué expectativas tenemos para conquistar el podio trabajando en la soledad del laboratorio de nuestro despacho o en la compañía de un equipo que acaba por cerrarse en sí mismo? 


\section{LA NECESIDAD DE 'NICHOS ECOLÓGICOS'}

En un territorio donde reina la borrosidad de la confusión y el barbecho, cabe abrirse paso desde la experimentación de nuevas formas de cultivo. Hace ya bastantes años que la luz del pensamiento crítico de S. Toulmin (1977) iluminó el camino a seguir por parte de aquellas disciplinas y campos del conocimientos precisados de una institucionalización a vida o muerte: la construcción de nichos ecológicos.

A poco que se analice la ingente y valiosa producción de trabajos de investigación en DLE, en los últimos 15 años, conocidos desde su divulgación en las más que destacables revistas profesionales españolas que hoy recogen nuestro avance, al igual que los trabajos presentados a nuestros congresos y simposios, etc., es fácil advertir que el contraste característico del quehacer científico cuando se procesan datos surgidos de diferentes investigaciones (con análogos o diferentes criterios metodológicos)- resulta más bien escaso a la hora de comparar los estudios que, realizados desde las tierras altas o bajas, centran sus respectivos objetivos en cuestiones de la misma índole: digamos problemas en el entorno del aprendizaje de una LE, problemas en el contexto del uso social de las LEs, problemas relativos a la construcción del conocimiento profesional docente y a su desarrollo profesional, etc. En su lugar, nos encontramos con una nutrida y variada interpretación de los problemas (casi siempre análogos) que se eligen como motivo de indagación. Tal situación parece mantenernos anclados, de una manera casi imperceptible, en la falta de consecución de un cuerpo del saber y del saber hacer que resulte firme y reconocido.

En realidad, lo asumamos en mayor o en menor medida o con más desagrado que agrado, se nos requiere no sólo acotar nuestro territorio investigador sino también construir un marco teórico que resulte comprensivo y contundente a la hora de proyectarlo en los trabajos empíricos que aviven el progreso del conocimiento en DLE en nuestro contexto inmediato de referencia: las LEs en la España de las autonomías y de las nacionalidades históricas y, sobre todo, en un Estado cuyos ciudadanos son miembros de pleno derecho de la Unión Europea, y, al tiempo, en el contexto amplio de la Unión. En este complejo mundo de contextos (sobre todo el segundo), es donde la DLE tiene que llegar, de hoy para mañana, a obtener el reconocimiento social. Y, como sabemos, tal tipo de reconocimiento es una de las condiciones imprescindibles para su consolidación y avance a favor de la conquista de la relevancia científica a que todos aspiramos. Este es, justamente, uno de los nichos ecológicos a que hacía referencia Toulmin. Pero no el único.

\subsection{De la lengua a la incorporación de quien la usa}

Nuestra utilidad (hoy, en términos neoliberales, habría que decir 'rentabilidad' para resultar políticamente correctos) también entra en el juego del reconocimiento. Supone otro nicho ecológico. De hoy para mañana, el avance en DLE no puede seguir condicionado, apegado, e inseparable del ámbito curricular del sistema educativo formal. Es cierto que hubo un tiempo en que creíamos que las LEs se 'enseñaban', como cualquier otro objeto de conocimiento. Y de aquellos lodos vienen estos barros. Hoy hay pocas dudas acerca de que lo que es objeto de enseñanza es la estructura sistémica de la lengua, siendo todo lo demás, todo lo que conduce a su uso social, objeto de aprendizaje o, más bien, como algunos preferimos matizar, objeto de un proceso de apropiación en situación de comunicación social 
no manipulada pedagógicamente. En aquel tiempo, no lejano y tal vez aún presente en buena medida, la DLE era una didáctica de la lengua. Y claro la didáctica del aprender a enseñar las partes de la oración, la formación de palabras, la construcción oracional en una LE, al igual que en la propia o propias, genera la misma estima profesional y social que la de aprender a enseñar las operaciones básica del álgebra bajo la creencia de que se está desarrollando un auténtico pensamiento matemático en los alumnos escolarizados.

El fracaso de la DLE centrada en la lengua, como hoy sabemos, fue rápidamente rentabilizado por quienes acertaron a incorporar al sujeto que busca apropiarse de una LE para una instalación social, transnacional, efectiva. Bajo el liderazgo de los primeros pasos dados por el Proyecto de Lenguas Modernas (Vivas) del Consejo de Europa, el desajuste social de la didáctica escolar de las LEs fue compensado por las prácticas funcionalistas y utilitaristas de las instituciones privadas que centraron su atención (económica, claro está) en el mercado de los idiomas. Claro que la DLE apegada al sistema educativo aprendió la lección y renovó sus planteamientos para, con una apreciable ayuda de los psicólogos de la educación, fundamentar su nueva andadura en torno a los enfoques comunicativos centrados en el usuario de la nueva lengua.

Y así, hoy en día, gozamos de las ventajas (indiscutibles) de una DLE más semiótica, donde todo se subordina al "acto semiótico" y a los diferentes parámetros que intervienen en su realización (el medio, el soporte, la situación, el estado social y afectivo de los locutores, etc.), lo que indica que la presencia del sujeto en el discurso es más importante para la comunicación que los objetos acerca de los que habla. Un concepto didáctico que insiste, ya desde la lingüística funcional de Michael Halliday, en la necesidad de proporcionar al individuo que aprende y perfecciona una lengua los medios para construir una personalidad como sujeto hablante en la lengua que aprende.

Hemos sabido, en definitiva, desarrollar una nueva estructura didáctica para las LEs que comienza tímidamente a combinar y conjugar los elementos lingüísticos y metodológicos de la lengua en cuestión con los planteamientos sociológicos y curriculares de quiénes son los que aprenden esa lengua, cuáles sus intereses, motivaciones y actitudes, qué tipo de finalidades presiden su proceso de apropiación de una forma de comunicar socialmente, cuáles son sus valoraciones interculturales respecto de las lenguas de comunicación social, etc. Una estructura que, a lo largo de sucesivas circunvoluciones, ha cristalizado en una serie de líneas maestras -trazadas desde un amplio consenso- contempladas en el documento europeo de referencia ineludible para la problemática que aquí nos ocupa: el Marco de referencia europeo para el aprendizaje, la enseñanza y la evaluación de lenguas (en versión al español, Instituto Cervantes, 2002).

Pero este hoy, que ya casi es ayer, tiene un valor relativo para nuestro mañana. No cabe duda que aquellos colegas que, bien desde áreas de filología bien desde la propia área de DLL, han mantenido viva la llama de la dimensión comunicativa de las LEs vinculada a planteamientos sociopragmáticos (en el ámbito lingüístico), a enfoques descendentes y al desarrollo de tramas creativas en el aprendizaje por tareas y proyectos (en el territorio metodológico), han situado a la DLE en nuestro país en un nicho ecológico de enorme singularidad y trascendencia para el desarrollo curricular y el desarrollo profesional de los docentes de LEs.

Aún así, albergo bastantes dudas acerca del avance que podamos seguir a partir de aquí en esta misma dirección. Y no son dudas que obedezcan a un talante de incontrolable pesimismo 
sobre el progreso en LEs en nuestro contexto inmediato (que admito sentirlo), sino más bien a un análisis realista de los datos de que disponemos. Porque, en realidad,

¿a qué otra situación distinta a una auténtica condición de 'fracaso' hemos llegado, de forma colectiva, en el desarrollo curricular de las LEs y en el desarrollo del conocimiento profesional docente del profesorado que está a su cargo?

\subsection{Una DLE crítica}

Tal vez sólo podamos asumir una respuesta de consenso si adoptamos, aunque sea de forma moderada, un planteamiento crítico. Y no está de más recordar aquí que la existencia de una corriente crítica en el interior de la propia Lingüística Aplicada (al igual que en el interior de la propia Pedagogía), no es novedad alguna y que muchos colegas del área, aún sin ser conscientes de ello, llevan participando de su juego dialéctico hace ya un tiempo.

Al igual que quienes militan en la lingüística aplicada crítica, el análisis del discurso crítico, la etnografía crítica, y tantos otros campos postmodernistas del hacer crítico, los didactas de LEs críticos no buscamos fragmentar aún más este territorio de borrosidad e indefinición: muy al contrario, nuestro objetivo es ayudar a enriquecerlo con este tipo de dialéctica. Y a quien se pregunte ¿por qué una DLE crítica en el desarrollo curricular de las LEs? no queda otro remedio que responderle que la razón reside en el hecho -probado ${ }^{6}$ - de que el territorio escolar de las LEs es un mundo de fracaso generalizado en cuanto a la expresión oral, que conduce a un fuerte grado de insatisfacción (de los alumnos, de su profesorado, del centro educativo, de los padres del alumnado, de la sociedad...) y que, en consecuencia, demanda transformaciones radicales al grito de iPor favor, no más de los mismo: no más teorías sobre adquisición y aprendizaje de LEs enraizadas en el análisis de espacios tan diferentes al escenario aular ordinario de los centros escolares (rurales -en su mayoría- y urbanos, públicos y privados) de nuestro país!

Claro,

- ...cuando uno observa que aquel objetivo central que ha estado siempre presente en el devenir histórico de la Linguística Aplicada -la resolución de problemas, en palabras de S. Pit Corder o Tatiana Slama-Cazacu (pioneros en este campo)- es un objetivo

${ }^{5}$ Se trata de una corriente desarrollada por Alastair Pennycook en 1990 y recogida en 1999 por Alan Davies en su libro An Introduction to Applied Linguistics: From Practice to Theory. Un libro que incluye en su glosario el término Critical Applied Linguistics bajo la explicación de: "una forma de pensar de algunos lingüistas aplicados que entienden que la LA convencional no acierta a implicarse y comprometerse con las necesarias transformaciones de la sociedad".

${ }^{6}$ Los datos de los Informes de las evaluaciones institucionales del INCE para el Inglés en toda España, o de una Comunidad concreta (como, por ejemplo, la investigación del ICEC, también para el Inglés en Primaria, diseñada y dirigida por M. Peñate Cabrera) revelan una falta de compromiso del profesorado y una falta de logro del alumnado respecto a la expresión oral-excepción hecha del uso de expresiones memorizadas, respuestas a preguntas cerradas, etc. El estudio que yo mismo he dirigido en Galicia sobre logros en competencia comunicativa oral, en Inglés y Francés, al término de la ESO, advierte que la expresión oral es la habilidad pendiente de profesores y alumnos en la vida del aula de LEs (cf. Vez y Martínez, 2002). La Tesis doctoral de L. Armán Lomba, recientemente defendida en la Universidad de Vigo, extiende esta misma situación a las circunstancias del Francés como segunda lengua extranjera en la ESO en el ámbito de la Comunidad gallega. 
cada vez más difuso hoy en día y que, en efecto, la LA poco resuelve en el campo del curriculum de LEs...

- ...y cuando uno es consciente de que las LEs siguen siendo 'lenguas-asignaturas', después de décadas de saber que el único modo viable de apropiarse culturalmente de una nueva lengua son los aprendizajes experienciales, en el marco de vivencias no manipuladas pedagógicamente para su explotación escolar en un aula...

- ...después de décadas de saber que la apropiación sociocultural en la escuela básica se produce a través de contenidos de otras disciplinas en la LE... y nunca a través de un aprendizaje analítico, academicista, reflexivo...

- ...cuando los esfuerzos del CCC (Comité de Cooperación Cultural del Consejo de Europa) en su primera etapa (de los setenta a finales de los ochenta) con su política de niveles umbrales bajo enfoques semántico-usuales, de corte nocional funcional y orientación comunicativa, sólo han servido para potenciar al Inglés como autopista de la comunicación transnacional en Europa...

- ...cuando en su último avance, de los 90 hasta hoy en día, el CCC nos propone un Marco Común de Referencia para las LEs muy centrado en la evaluación de estándares de competencias certificables (algo que está entusiasmando mucho más a las grandes multinacionales de la industria de los idiomas en Europa y fuera de ella -como las grandes beneficiarias que son del fracaso escolar de las LEs- que a los propios profesionales del sistema educativo)...

- ...cuando el paradigma de la globalización en Europa vía English a costa de otras lenguas europeas, tan bien descrito por Phillipson ${ }^{7}$, gana terreno a una necesaria política curricular europea más centrada en un paradigma lingüístico ecológico, y amenaza a una política defensora de la pluralidad linguiística y la interculturalidad como garantía de su identidad como tal Unión Europea...

- ...entonces... uno siente una profunda y creciente insatisfacción... y a fuerza de resistirse a una cultura de reproducción de lo establecido... se vuelve crítico.

Tal vez encontremos en la militancia crítica en DLE, moderada y no beligerante, otro nicho ecológico que permita, tanto a los lingüistas de profesión (en áreas de conocimiento de Filología o en Lengua Española) que desarrollan la dimensión didáctica con auténtica vocación (aunque sea en su tiempo libre) cuanto a los didactas de LEs (hoy todavía adscritos administrativamente al área de conocimiento de DLL por razones que espero no duren mucho más tiempo), encontrarnos trabajando colaborativamente más allá de un espacio de libre expresión de nuestras ideas, como el que hoy nos proporciona esta recién nacida revista de integración cuyo propio nombre -Porta Linguarum-ilustra a la perfección el creciente espíritu de solidaridad interdisciplinar e interlingüística.

Me refiero a un trabajo colaborativo a favor de la consecución de un nicho ecológico para la construcción de nuestro conocimiento compartido en DLE a favor de la superación de los retos que mañana (hoy) van a demandar nuestra intervención transformativa en nuevos espacios y en nuevas formas de hacer que exige redoblar nuestros esfuerzos

7 Tanto en su trabajo seminal Linguistic Imperialism, editado por OUP, cuanto en su reciente libro English-only Europe? Language policy challenges, editado por Routledge. 
comunes de unidad y discusión científica. Pero de ello tratará el final de mi reflexión. Así que permíteme ahora, tú lector, regresar al punto en el que se ha quedado interrumpido mi análisis del avance de ayer a hoy para entrar en una circunvolución más del progreso de hoy para mañana.

\subsection{El espacio de la DLE en el ámbito profesionalizador}

Exponía, antes de deslizarme por la pendiente de la pasión crítica, que el fracaso en el territorio del desarrollo curricular y del desarrollo profesional docente nos está alertando acerca del hecho de que el territorio de las LEs es un gigante con pies de barro. Salimos (¿?) de un estado de cosas en que, casi sin saberlo, hemos estado cercados no sólo por las tomas de decisiones alrededor de los intereses que constituyen los saberes curriculares (técnicos y transmisivos, o bien prácticos y reflexivos, o (mejor) críticos y transformativos... empleando la terminología de Habermas) sino también, y sobre todo, por intereses económicos y políticos. Aún así hemos sabido navegar en esas aguas con la esperanza puesta, tal vez, en la simple aventura (¿profesional?) de surcar los procelosos mares de la DLE. Pero como decía Fernando Pessoa, insigne poeta e ilustre pensador portugués, un barco da la impresión de ser un objeto que tiene como finalidad última la de navegar, si bien su verdadera finalidad no es la de navegar sino la de arribar a un puerto seguro. Los didactas específicos en LEs no somos navegantes que simplemente surcamos los mares de la educación como meros aventureros. Aprender a enseñar LEs no es tan sólo una singladura marinera por las aguas de la formación inicial y permanente de esta profesión incierta. Aprender a ser profesor, y serlo en particular de un área tan sociocomunicativa e intercultural como son las LEs, implica la adopción de un rol social.

\section{¿Qué quiero decir con esto?}

Un profesor de lenguas hace algo más relevante que 'enseñar un idioma'. Es un agente clave en los procesos sociales y, por tanto, tiene que incorporar en su formación la perspectiva social de su tarea docente. Y, porque resulta un agente esencial en el proceso social de la comunicación y representación transnacional e intercultural, debe asumir esa perspectiva social que se deriva del rol que juegan las lenguas en los procesos de transformación de una comunidad, de todo un pueblo, y, en definitiva, en el proceso de transformación global de la comunicación que caracteriza a la postmodernidad.

Esta perspectiva social de la profesión ayuda, pienso yo, a ver que aprender a enseñar es algo que está mucho más allá de unas cuantas técnicas metodológicas y de gestión de aula... más allá de un conocimiento parcialmente especializado sobre la didáctica de las LEs. Por ello, el mundo de ayer -etiquetado bajo el rótulo anglosajón de "teacher training" y en el que se nos ha querido encasillar a quienes venimos profesando en DLE- está dejando paso a la incorporación de todo lo que se esconde bajo el rótulo (también anglosajón) de "teacher education" (Widdowson, 1983: 19), y que nosotros aquí denominamos 'formación y desarrollo profesional del profesorado'.

Mucho se ha discutido (aunque el escenario del debate se haya limitado casi siempre al espacio propio del tertuliano) sobre si la DLE debe vincularse a la LA, e indirectamente a la Filología o a la Linguíística; de si tenemos una cierta necesidad de aggiornamento y de una desenfadada actitud de aceptación de la generosa (¿?) ayuda de los psicólogos de la educación 
especializados en cuestiones de nuestro ámbito ( $₫$ ?); de si debemos hacer oídos sordos y cerrar los ojos ante las tentadoras propuestas de mayor conceptualización de los contenidos del área que nos puedan llegar de los didactas generales; en fin, de si debemos hacer lo que a nosotros nos dé la real gana y punto.

$\mathrm{Y}$ en este debate de tácita ocultación de intereses (los de unos y los de otros) no tiene casi nunca cabida la simple y llana cuestión de...

¿Qué sería de cualquier didáctica específica, la DLE incluida, si no existiese el desarrollo curricular y la formación y el desarrollo profesional del profesorado (esas cosas de los pedagogos...)?

¿Hubieran sido creadas alguna vez como áreas de conocimiento?

De ahí que la definición del espacio de la DLE en el ámbito profesionalizador no pueda nunca convertirse en una cuestión de si es a tirios o a troyanos a quienes sirve: el problema es tan simple como afirmar que, en principio (y al margen de otros espacios a los que, más adelante, haré referencia), donde quiera que esté ubicado el desarrollo curricular, la formación del profesorado y el desarrollo profesional de los docentes, allí encontrará su ubicación natural cualquier didáctica específica, y allí tiene la DLE una de sus posibilidades de crecimiento, de manera responsable, con toda la autonomía de que precise, desde la docencia y la investigación (una y otra no sólo de calidad sino, a poder ser, de excelencia).

\subsection{DLE y las competencias profesionales}

Al tiempo, y por otra parte, cabe tener en cuenta que existe un nivel de la práctica profesional que tiene que ver con el propio escenario de la intervención didáctica en LEs. Un nivel que va más allá del de la teoría y la práctica. Más allá de la práctica en el sentido de instruir a quienes se forman para ser profesores de LEs, y más allá de la práctica en el sentido de lo que realmente ocurre en el escenario aular de cada día. Un nivel que configura en sí mismo otro nicho ecológico para la DLE. No podemos poner en duda que los requisitos acerca del profesor en su puesto de trabajo están definidos por la situación social que caracteriza a su aula de lengua extranjera, y claro... el contexto del aula en realidad no es otra cosa que un fiel reflejo de aquellas problemáticas sociales que prevalecen en la sociedad.

Y así, en este nivel de la práctica tan escasamente atendido la cuestión de la competencia profesional se transforma en un concepto social porque la realidad social es la que condiciona plenamente los procesos de interacción social en el escenario que se les da a los docentes: un aula. De ello saben mucho y bien aquellos que, con su destino de profesor de lengua extranjera en un centro rural de una provincia interior y profunda, imaginan los excelentes trabajos por tareas y proyectos que se podrían hacer en un centro de la Costa del Sol o de las Islas Canarias. Y es que la realidad profesional de un aula de LE puede llegar a ser extremadamente dura, y marcar nuestra profesionalización docente, en la medida en que el éxito o el fracaso de su proceso de apropiación pueda llegar a depender casi por entero de las circunstancias del entorno social en que se circunscribe. Como ya señalé en otra ocasión (Vez, 2001a: 167):

...es esta situación general del contexto social la que influye más poderosamente en la apreciación de que unos profesores resulten más competentes que otros y, naturalmente, no por su propio fracaso como profesionales sino por razones estruc- 
turales que están más allá de su control. Este parece ser el caso de lo que está sucediendo en nuestro país en relación al desarrollo de nuevas experiencias de aprendizaje vivenciales mediante tareas y tramas creativas de naturaleza procesual.

De ahí que ser y ejercer como docente de LEs también es, además de lo que todos sabemos que es, una opción política. Una opción política frente a las desigualdades. Y las desigualdades no están ahí para ser constatadas. Están ahí para resistirnos a ellas, primero, y para transformarlas después.

$¿ O$ alguien pone en duda que el ámbito de los aprendizajes de lenguas es un mundo de desigualdades en la presente sociedad de la cultura del mestizaje?

\section{LA dimensión europea de LA DLE}

Soy de los que opinan que los tiempos que corren en el mundo de los aprendizajes de LEs van a exigir, están exigiendo ya, el abandono de todos los simplismos con los que nos hemos estado moviendo en décadas pasadas. Son tiempos, parafraseando a Savater (1997), que demandan de una complejidad intelectual que sea capaz de dar cuenta de la complejidad real que suponen las LEs. Una complejidad que, en el ámbito de la dimensión europea, es de especial relevancia. En realidad, como un nicho ecológico más en el que anclar la institucionalización de la DLE, los recientes avances que en estos últimos años se vienen produciendo en el territorio de las LEs bajo el impulso de las variadas acciones del Consejo de Europa, nos marcan una ruta a seguir en la construcción del mañana de nuestra disciplina, un extraordinario foco de interés que incorpora a nuestros objetos de investigación los nuevos conceptos de competencia en LEs, de evaluación de esa competencia, de niveles comunes de referencia, de escenarios de aprendizaje y adquisición, de problemas de enseñanza y tareas de desarrollo, de usos y usuarios de una LE, de diversificación lingüística y desarrollo curricular, de interculturalidad... Como en otro lugar (Vez, 2002a: 147-148) he mencionado,

In a Europe that strives for unity in more and more fields of human enterprise - cultural, economic, juridical and perhaps even political-communication between member states and, at the grass-roots level, between individuals across borders and cultures is of the most vital importance. In all the challenges offered to us by the growth towards real integration of the various nationalities into what Churchill already called "The United States of Europe", a reasonable spoken and/or written command of at least two, if not even three, languages spoken within its perimeter takes absolute priority. Without it the free movement of persons becomes a hollow phrase. A policy aimed at making one or two major languages the exclusive means of communication across state borders at the expense of many others will only seemingly simplify European integration. Refusing to meet the challenge of maintaining a liberal diversity of languages and cultures will not only culturally impoverish the Europe of the future, it will also cause resentment on the part of the minority language communities. Foreign language learning and teaching, also of minority languages, giving explicit attention to the socio-cultural aspects of the target language community, therefore, will remain a central task of education -in particular, teacher education- in European member states and deserves a lot of attention and investment of means. 
Si tenemos en cuenta los tres vértices en que, siguiendo a Moravsky (1990), se inscribe la didáctica de las lenguas (la lengua en cuestión, el desarrollo cognitivo de quienes la usan o tratan de hacerlo, y la realidad social), nuestro hoy-mañana está asumiendo, de manera lenta pero progresiva, el interés por la LE como comportamiento intercultural, como compromiso en la acción intercultural. Los últimos años del siglo -y los años venideros- nos llevan, finalmente, a comprender la lengua como comportamiento intercultural -una herramienta para desarrollar nuestras interacciones interculturales en una cultura del mestizaje. Y nuestra perspectiva se vuelve sociológica. Nuestra preocupación inicial por el "locutor nativo" (que, en realidad, no quiere decir mucho) se ha trasladado, de la mano de una sociedad global de la información, de la educación y del mestizaje, a un "locutor intercultural".

\subsection{Una DLE más sociológica}

A medida que la ciencia lingüística se vuelve más sociológica, sus aportaciones penetran más y mejor en un intento por afrontar ese lugar de encuentro que pasa por establecer y definir las relaciones entre lenguaje, cultura y sociedad. Las lenguas no se emplean en una cámara de vacío, sin contexto alguno, ni en contextos virtuales; más bien, su uso responde a la acogida de los contextos discursivos que, necesariamente, están siempre impregnados de la ideología de los sistemas e instituciones sociales. Con el desarrollo de la orientación comunicativa, la DLE alcanzó a una forma tácita de consenso entre teóricos y prácticos sobre el hecho de que este componente sociológico complementa y modifica los nuevos enfoques de la enseñanza y aprendizaje de una LE, si bien no parece existir la misma base de acuerdo en torno al problema de cómo combinar, de manera efectiva y práctica, un enfoque comunicativo y un enfoque sociológico.

En el marco del creciente movimiento mundial en torno a una mayor comunicación intercultural, el papel de las LEs ha venido a cobrar una identidad, todavía más remarcada, en cuanto a su dimensión de co-responsabilidad social en la construcción de esa perspectiva intercultural. Una perspectiva que, como sabemos, está ejerciendo un peso específico en la potenciación de la dimensión europea ${ }^{8}$. Sin duda, estamos ante un hecho sociológico de una especial trascendencia, con ventajas y riesgos que debemos asumir como componente natural de nuestros conocimientos propios y de nuestras tareas de investigación en DLE. El proceso de vivir los usos lingüísticos, no sólo demandado desde la propia subsistencia de las lenguas minorizadas sino también como ingrediente básico en el desarrollo social de la comunicación transnacional europea por medio de lenguas auxiliares (las LEs), depende en gran medida de que la lengua en cuestión (propia o extranjera) exprese una cultura viva y compartida.

En consecuencia, si bien es posible argumentar que, en principio, la enseñanza de una LE es la enseñanza de una herramienta para ciertos usos instrumentales, sin implicaciones sociales ni ideológicas, en la realidad sabemos que el éxito de estas enseñanzas -digamos, la efectiva apropiación de la lengua y del comportamiento social en esa lengua- depende mucho de que los aprendices sean capaces de integrar los elementos lingüísticos con sus propias necesidades ideológicas y sociales. Claro que la determinación a priori de tales necesidades, su desarrollo en el aula, su evaluación, etc. es todavía un terreno poco explorado. De hecho,

${ }^{8}$ El Marco y el propio Portfolio insisten en esta cuestión de forma clara y fundamentada. 
los datos a día de hoy revelan que España, en su conjunto, y salvando la excepción de aquellas iniciativas que se están llevando a cabo en Cataluña o las que se producen desde el Observatorio Janua Linguarum para las LEs de la Universidad de Santiago ${ }^{9}$, manifiesta un retraso considerable en relación a la dinamización (conceptual y práctica) de Portafolios (que ya se vienen utilizando en varios estados europeos desde 1997), a la adecuación de diseños y desarrollos curriculares a la nuevas exigencias derivadas del MECR, a la elaboración de descriptores de niveles comunes de referencia en diferentes LEs para el campo de las profesiones, de la educación no formal, etc.

\subsection{Más allá de la 'unidad didáctica'}

Hubo un tiempo en que la didáctica de las LEs era la didáctica de la 'unidad didáctica'. $\mathrm{Y}$ no fueron malos tiempos, en la medida en que los anteriores no eran otra cosa que la enseñanza instrumental de un idioma al margen de su interés y sus circunstancias en el mundo educativo vinculado al desarrollo curricular. En aquel contexto, los aprendizajes efectivos de las LEs se orientaban -bajo nuestra DLE instrumental- en la dirección de esperar a que el encuentro social, un duro crisol de competencia de la apropiación de la nueva lengua, se llegase a producir un día (¡para muchos aprendices un día que nunca llegaron a ver amanecer!) en alguna situación real muy alejada del contexto aular.

Bajo la 'didáctica de la unidad didáctica' se trató muchas veces de motivar ficticiamente (si, en realidad, existió alguna vez tal motivación extrínseca) a los alumnos escolares a aprender una LE para cuando tuviesen ocasión de ir a un país donde esa lengua tuviese una instalación social plena. Claro que hoy sabemos que estos deben estar preparados para el encuentro social en el discurso desde el primer momento de su proceso de contacto con la nueva experiencia lingüística en la lengua en cuestión, aunque esto suceda en un aula ${ }^{10}$. Y de hoy para mañana reconocemos que el aprendizaje efectivo de LEs no es el que responde a una secuencia de unidades didácticas (la unidad didáctica 2 que sigue a la 1 y precede a la 3) diseñadas para el alumno, desde fuera del alumno, sino el que busca un desarrollo sostenible que incorpora todos los rasgos cognitivos del sujeto (emociones incluidas) en el marco de acciones vivenciales auténticas. Acciones vivenciales que, en el contexto de la dimensión europea, pasan por tareas, procesos, estrategias y tácticas centrados en el 'contexto mental' de un locutor europeo que se prepara, como locutor intercultural, para hacer frente a aquellos retos - de hoy y de mañana- que se derivan de la construcción de una Europa unida en la diversidad de nuestras diferencias lingüísticas y culturales.

Ir más allá de una didáctica de unidades didácticas al uso, requiere que la DLE se implique en consensuar procesos de formación y profesionalización del profesorado orientados

${ }^{9}$ El Observatorio Janua Linguarum, creado en 2003 en el ICE de la Universidad de Santiago de Compostela, está a cargo de un grupo mixto formado por investigadores de universidades gallegas y diferentes agentes del sistema educativo que, bajo mi dirección, centran su atención en diversas problemáticas actuales de las LEs. Para mayor información, consúltese 'Grupos de Investigación' en http://iceusc.usc.es

${ }^{10}$ Las investigaciones en aulas de Inglés de Ed. Primaria llevadas a cabo por M. Valcárcel, M. Verdú y Y. Coyle, de la Universidad de Murcia, revelan de un modo excelente no sólo que, efectivamente, esto sucede, sino el modo en que llega a suceder en aulas normales y corrientes. Cf., entre otros de sus trabajos, Coyle, Y., M. Verdú y M. Valcárcel (2002). 
hacia la adquisición y el desarrollo de las destrezas básicas de la negociación. "Negociación" es el término empleado ya hace un tiempo por Candlin (1981) para describir el conjunto de complejos dominios (de tipo actitudinal, cognitivo, intelectual, pragmático, intercultural, lingüístico, etc.) que deben ser desarrollados y gestionados por un alumno de lengua extranjera durante su proceso de formación para prepararse para su encuentro con el discurso social. Un proceso formulado igualmente por Edelhoff (1980: 64) en los siguientes términos:

...aprender acerca de los demás, sus creencias, sus motivaciones, su pasado, su contexto histórico, su cultura y sus ideales. Es la experiencia de los demás con lo que el aprendiz tiene que aprender a enfrentarse, de manera que el proceso de percibir las experiencias de otras personas le proporcione un nuevo nivel para construir su propia experiencia.

En este sentido, la dimensión intercultural europea debe integrar y potenciar, de hoy para mañana, la toma de conciencia sobre el papel de las LEs (de varias LEs) como un instrumento social que proporciona a los aprendices, del sistema formal o no formal, jóvenes escolares o adultos profesionales, la oportunidad de desarrollar sus capacidades como experimentadores y negociadores más que como receptores pasivos de datos y tópicos netamente lingüísticos. Los objetivos de formación, a corto, medio y largo plazo, que competen al desarrollo de un potencial comunicativo por parte de los alumnos de LEs - no sólo como alumnos sino también como comunicadores sociales- forman parte explícita, hoy en día, de la inmensa mayoría de los diseños curriculares de los diversos sistemas educativos europeos que, de forma progresiva, se han venido aproximando, a lo largo de las última décadas, a la proyección de una educación lingüística vinculada, estrechamente, a la dimensión de un "yo socializado" en el aprendiz de LEs. La DLE también tiene que incorporar unos contenidos (de conocimiento y de habilidades) acorde con estas circunstancias de progreso que van mucho más allá de cuando diseñábamos, o ayudábamos a diseñar, unidades didácticas destinadas a una intervención docente en LEs de tipo academicista.

\subsection{El contexto social}

Como en estos últimos años tratan de poner de relieve las experiencias de aprendizaje de LEs siguiendo pautas vivenciales, el proceso de apropiación de una nueva lengua se inserta en la esfera social de las propias vivencias de los alumnos. Y si no es así, posiblemente no va mucho más allá de ser un tipo de conocimiento más. De ahí la importancia de cultivar, en el tránsito por este proceso, las capacidades de los alumnos para desarrollar estrategias discursivas, sobre la base de una comunicación adecuada, intercultural y efectiva. Algo que, no cabe duda, va a afectar a su gramática social ya adquirida en la medida en que va a extender y modificar -en todo caso, integrar- sus percepciones iniciales de los códigos y subcódigos lingüísticos que ya forman parte de su competencia.

Sobre la base empírica, y no verificada, de la teoría de la relatividad lingüística, descansa el aserto común e implícito en el ámbito de los aprendizajes de lenguas de que no puede existir una competencia sociolingüística y pragmática en LEs sin que tenga lugar, por parte del alumno, la interiorización de los patrones y valores culturales de los hablantes de esa lengua. Claro que el interrogante sobre tal implícito parece obvio: ¿qué hablantes?; ¿qué patrones? y ¿qué valores?. Parece evidente que los materiales didácticos y las metodologías 
del aula deberían reflejar, al menos, algunos de los siguientes rasgos concernientes al aprendizaje de una LE como forma de comunicación, si se pretende que los alumnos desarrollen sus capacidades para afrontar los problemas de la dimensión social e intercultural vinculada a tales aprendizajes lingüísticos. En el marco de una dimensión europea, más allá del diseño e implementación de unidades didácticas, los profesionales de la DLE deberíamos asumir y hacer asumir- el hecho de que:

- la mediación en la derivación del significado es un proceso dinámico de inferencia;

- (como consecuencia) los significados son plurales y variables en la medida en que se desarrollan las características concretas del proceso de comunicación;

- un proceso de negociación de significados está determinado por reglas discursivas de tipo social y específicas de una cultura (y por reglas de tipo pancultural) que constituyen una ayuda esencial en el aprendizaje y progreso lingüístico de apropiación de una nueva lengua;

- este tipo de reglas entran en juego a través de procesos de interacción y, como consecuencia, las estrategias de apropiación de la LE deberían enmarcarse en la dinámica de un contexto transaccional;

- los alumnos de una LE necesitan desarrollar una cierta sensibilidad hacia los prejuicios sociales y culturales que conllevan determinados actos de habla, y que una sensibilidad de este tipo -que se puede impulsar mediante el diseño de contenidos específicos de tipo actitudinal- resulta un prerequisito básico para comprender la nueva lengua como un medio de traspasar el umbral de la comunicación intercultural que, de hoy para mañana, supone el mayor rasgo de nuestra identificación como europeos.

Sin duda, el "contexto social" no nos conduce a una tierra prometida en el ámbito de los aprendizajes lingüísticos pero, desde el punto de vista de las estrategias procedimentales de la enseñanza y aprendizaje de nuevas lenguas, pone de relieve algunos aspectos concretos que merecen su atención dentro del marco profesionalizador europeo hacia el que (creo) debe dirigir su atención la DLE en nuestro país. En particular:

- Los contextos (académicos o no académicos) en los que hoy se desarrollan los aprendizajes de LEs son muy variados y diversos entre sí, lo mismo que lo son las necesidades lingüísticas y los propios propósitos de aprendizaje de una lengua añadida. Si se pretende buscar un denominador común a todos ellos en Europa, sin duda nos pondríamos fácilmente de acuerdo en formularlo en la dirección de un amplio movimiento social en favor de una comunicación transnacional e intercultural, asumiendo -desde luego- las ventajas y los riesgos de esta opción.

- Esta opción, pone en tela de juicio el debate secular en torno a la relación entre lenguaje y sociedad. No se pone en duda que el lenguaje y las lenguas tienen su realización en un contexto. Pero no sólo en el contexto del texto, sino también en un contexto enriquecido a nivel etnográfico que, de algún modo, es preciso trasladar didácticamente al contexto del aula de LEs. De ahí la importancia que, recientemente, se viene observando en la creciente preocupación del profesorado de estas lenguas (y de sus formadores en DLE) por desarrollar en los alumnos un sentido, una conciencia, centrada en competencias sociales, que les permita llegar a dominar usos en la nueva lengua que resulten apropiados y pertinentes no sólo dentro del amplio sistema universal 
de aquellos valores socioculturales en los que hoy se desarrolla la comunicación sino también, de modo muy singular y específico, en el ámbito de la conciencia europea.

- Claro que el discurso social y la cultura son, a su vez, algo más que el telón de fondo y que el contexto de la significación en una lengua franca. Apropiarse de una lengua añadida es apropiarse de sus discursos sociales y de su cultura. Ello implica penetrar en la dimensión del lenguaje y las lenguas como un instrumento social bajo una perspectiva que sitúa los propios conceptos de lengua, discurso social y cultura en una dinámica de correlación interna que une estos tres conceptos a la hora de compartir la característica común de la imprevisibilidad.

Este rasgo de "situaciones imprevisibles" que comparten los conceptos de lengua, discurso social y cultura nos ponen en guardia, en el ámbito de la DLE, ante la necesidad de impulsar los procedimientos y las destrezas de "la negociación" como fuente de toda acción didáctica y metodológica enfocada hacia un proceso efectivo de apropiación de la lengua extranjera, más allá de lo que implica las limitaciones derivadas de una unidad didáctica.

\subsection{Más allá del aula convencional de LEs}

Poco nos hemos preocupado, quienes hoy profesamos en DLE, de la importancia del escenario en donde tienen lugar los procesos, estrategias, tácticas y, ¡a veces!, los aprendizajes efectivos de una LE. Y cuando lo hemos hecho ha sido, casi siempre, para entender y hacer entender que es posible trasladar al aula todo aquello que forma parte del desarrollo de nuestros avances en el marco del contenido conceptual, o de nuestras propuestas más innovadoras en el territorio procedimental del conocimiento didáctico del contenido. Pero el aula de LEs, como cualquier aula, es un escenario donde realmente caben muy pocas de las ideas-acción que provienen de nuestras actuales investigaciones en DLE. En realidad, es un espacio que nos informa permanentemente, desde el análisis de la práctica que se deriva de la reflexión en la acción y la reflexión sobre la acción, de la inutilidad de tantas de las propuestas que construimos en el mundo universitario. Claro que nuestros oídos son sordos a las voces de quienes trabajan en las aulas de LEs y nuestros ojos no ven lo que en ellas ocurre, porque no las observamos o no lo hacemos suficientemente. Tal vez ha sido así de ayer a hoy pero -qué duda cabe- no puede seguir siéndolo de hoy para mañana.

Williams y Burden (1997: 202) nos dejaron, hace ya unos años, una interesante descripción acerca del tipo de atmósfera de aprendizaje que deben tratar de crear los profesores de LEs en sus aulas:

Las aulas de LEs, en especial, deben ser lugares donde resulte factible animar a los aprendices a usar la nueva lengua como forma de comunicación, a ensayar formas nuevas de construir y expresar los significados, a negociar, a cometer errores sin temor, y a aprender a aprender de los éxitos y de los fracasos. Desde un punto de vista emocional, un ambiente apropiado para el aprendizaje de lenguas sería aquel que potencia las dosis de confianza necesarias en el acto de la comunicación y que impulsa la seguridad y la auto-estima.

Claro que las aulas de que disponen los profesores de LEs del sistema educativo ordinario, aquí o en cualquier otro lugar (habida cuenta de que existen contextos que hacen pertinente 
la excepción), es un tipo de espacio radicalmente distinto del escenario en el que la apropiación real -la apropiación cultural- de una o varias lenguas tiene lugar cada día, para cientos de miles de seres humanos desde que el mundo es mundo. De ahí las dificultades para construir esa atmósfera de aprendizaje que exigen las LEs como manifestaciones esenciales de una sociedad de la cultura. Tan distinto es que, como en otra ocasión mencioné (Vez 2002b: 6),

En nuestro espacio de trabajo ordinario, apenas podemos hacer otra cosa que avanzar en la dimensión escrita de las lenguas y lograr cierto éxito en la dimensión comprensiva oral de su apropiación efectiva, como manifestación de un comportamiento cultural. Y porque es tan distinto, confiamos en que los espacios de la vida real completen nuestra tarea docente e, incluso, animamos indirectamente a nuestro alumnado -y, en definitiva, a sus padres- a invertir en esos otros espacios -ambientados en la propia realidad social de la lengua- como lugares de rentabilidad lingüística -con el ocio y el deporte como elementos de valor añadido- en la nueva y boyante sociedad del mercado de los idiomas.

De hoy para mañana, en el contexto de la dimensión europea, el aula de LEs no puede dejar de concebirse como un escenario psicosocial de interacciones y negociaciones significativas que sirva realmente al propósito de que los alumnos (sea cual sea su estatuto como tales) puedan ser capaces de construir su conocimiento del mundo (en principio, y sobre todo, el mundo de la Unión Europea que es su referente inmediato) desde la pluralidad linguística y la interculturalidad. Y esto es más que la simple orientación de los enfoques comunicativos tan apreciados por nuestra DLE en las décadas de nuestro ayer más inmediato. Como seguía diciendo en aquella ocasión (p. 7-8):

No debemos olvidar que los denominados enfoques comunicativos, de fuerte corte instrumental, utilitarista y funcionalista, nos han dejado una herencia que en poco o nada ayudan a la construcción de una sociedad de la cultura. ¿O es que acaso el actual dominio absoluto del Inglés, como lengua franca por excelencia de la sociedad neoliberal y mediática, de la sociedad digital, no es el resultado real y efectivo de los enfoques comunicativos de las últimas décadas? ¿Qué otra lengua se ha beneficiado en igual medida de tales enfoques? ¿Qué otra dimensión cultural se ha dejado sentir con semejante fuerza y aprecio que no sea la cultura global vía English? ¿Es que, acaso, las aulas de LEs de hoy en día, sobre todo en Infantil y Primaria, no son el resultado del contexto reproductor de una dimensión cultural que se nos da como casi única o incluso superior?

La atención al aula de LEs, a nuestras aulas, no ha pasado desapercibida al mundo de la investigación aplicada a la enseñanza y el aprendizaje de las LEs. Es cierto que una buena parte de estas investigaciones no han tomado el aula como punto de referencia, en la medida en que sus objetivos se han venido centrando en otro territorio de la actividad en LEs que a nosotros, los docentes, nos pilla más a trasmano. Me refiero a la rica y bienvenida investigación de los contextos naturales de adquisición de una nueva lengua. Un tipo de investigación que ha sido muy motivadora para muchos de nosotros, ha llenado de libros y artículos las estanterías de nuestra biblioteca, pero -en definitiva- no nos ha ayudado tanto como de ella esperábamos para resolver esos problemas que, día a día, nos preocupan y que, curso tras curso, se repiten bajo los mismos esquemas, o como sucede con los virus informáticos, bajo nuevas mutaciones. Pero no es menos cierto que, aunque sea menor y haya sido considerada de diferente calidad, 
otra buena parte de la investigación en lingüística aplicada ha dirigido su mirada hacia el mundo de los aprendizajes lingüísticos en el contexto del aula.

En realidad no estoy hablando de novedades de última hora. La atención al contexto y el aula es nuestro contexto más inmediato, seguido del entorno educativo del centro, de la comunidad educativa a la que pertenece el centro, etc.- tiene sus orígenes en los planteamientos de alguien a quien sólo conocemos y reconocemos por la etiqueta de 'competencia comunicativa' que le atribuimos como original. Pero Dell Hymes, que escribió su artículo germinal en 1972, y desde luego nunca lo hizo imaginando en lo más mínimo que iba a convertirse desde su título -“On communicative competence"- (Hymes, 1972) en una auténtica etiqueta de mercado, dedicó una mayor atención al contexto, si bien es menos conocido por ello en nuestro mundo profesional de las LEs.

$\mathrm{Si}$ es posible, además de conveniente, tender un puente entre las investigaciones en lingüística teórica y las aplicaciones al aula de LEs, resultará del máximo interés dedicar más atención a la cara desconocida de la obra de Hymes: su perspectiva sobre la importancia del contexto. En Abril de 1982, una década después de dar a conocer su bien conocido y breve artículo, Hymes -que ya había dejado bien sentadas sus firmes convicciones en relación a los enfoques etnográficos en el ámbito sociolingüístico (Hymes, 1974)- afirma que con la incorporación...

...del análisis del contexto en la lingüística teórica sería factible transformar los derroteros de la ciencia lingüística hasta el punto de permitir desarrollar en su interior los planteamientos de la etnografía del habla u otras perspectivas sociolingüísticas. (Hymes, 1982: 14).

Nos basta con observar los avances en los fundamentos lingüísticos que se han producido bajo el paradigma de la Pragmática y el Análisis del Discurso, incluida su aplicación a la enseñanza de LEs (cf. Vez, 2000, parte cuarta), para disipar dudas acerca de la visión cuasi profética de Dell Hymes. Pero, además, cabe tener en cuenta que buena parte de las investigaciones en lingüística aplicada que se desarrollan a partir de mediados de los años ochenta, comienzan a reconocer el interés del contexto como el concepto que mejor da cabida a todas las derivaciones de los planteamientos de la etnografía del habla, no sólo en escenarios naturales de uso de la lengua sino también en el aula de los centros escolares. Por ejemplo, Kramsch (1995), desde un análisis muy centrado en la pragmática, nos ha dejado recientemente una nítida y convincente visión de la noción del contexto en lenguas extranjeras con una atención muy particular a los escenarios del aula escolar, y la necesidad de redefinir los límites del estudio de la lengua en tales escenarios. Spolsky (1990) propuso un conjunto de condiciones necesarias para poder llegar a establecer una teoría sólida sobre los procesos de enseñanza-aprendizaje-adquisición de nuevas lenguas. Y, claro está, el contexto y la necesidad de investigar empíricamente el contexto, es una de tales condiciones.

Saville-Troike (1989), combinando rasgos propios de una perspectiva sociolingüística y otra antropológica, centra su atención en el comportamiento comunicativo que se produce en varios contextos culturales y dedica una parcela de su estudio al contexto cultural de las aulas en los sistemas educativos. Pero, sin duda, el trabajo de Rod Ellis (1987, 1990, 1994, 1995) resulta el más germinal en este ámbito. Y no sólo por llegar a resultar bien conocido en nuestro mundo profesional (sobre todo por parte del profesorado de Inglés), sino también por el efecto de sus propuestas a lo largo de la década final del siglo pasado. Como sabemos, Ellis 
tuvo la virtualidad de conseguir aunar en un discurso claro y sólido los presupuestos de investigadores especializados en el contexto de trabajo de las LEs (algunos de tan difícil y controvertida aceptación como es el caso de Krashen) y los presupuestos de los propios profesores de a pie que, de diferentes modos, han aprovechado sus aulas de LEs para desarrollar trabajos de investigación-acción o de otro tipo y, así, contribuir al desarrollo de una sana relación teoría-práctica centrada en el complejo proceso de enseñanza-aprendizaje-adquisición de las LEs.

Partiendo de la aceptación de la importancia del contexto en la actividad de las lenguas añadidas a la propia o propias, Ellis (1987: 3) ha desarrollado dos propuestas distintas sobre esta cuestión. La primera centra su interés en el interrogante:

¿Cómo y hasta qué punto el estudio del contexto puede arrojar luz sobre la apropiación del código de la nueva lengua?

El elemento nuclear que sirve de foco a su investigación para resolver este interrogante es el proceso de desarrollo de la competencia lingüística. La segunda trata de otra cuestión que a los docentes de LEs nos resulta de mayor interés:

¿Qué información nos puede facilitar el contexto social para revelarnos datos acerca de la manera en que los aprendices de una nueva lengua pueden llegar sin grandes dificultades a ser capaces de desarrollar sus ideas en esa lengua?

En este caso, el foco no es simplemente la estructura lingüística sino, fundamentalmente, las competencias que desarrollan los aprendices de LEs en el uso de la lengua para propósitos sociales y no para simples rutinas pseudo-comunicativas como las que tanto abundan en el aula.

Una dirección que tiene en cuenta, como rasgos esenciales, el hecho de que se facilita el desarrollo personal y se ayuda al alumnado a adaptarse al cambio social que implica la apropiación de una forma de comportarse no sólo de forma comunicativa sino, sobre todo, interculturalmente. Claro que para ello necesitamos otro punto de consenso: el espacio aular, el taller de trabajo. Si históricamente, los arquitectos escolares y las autoridades educativas han percibido los espacios de trabajo de la educación física, musical, plástica, en ciencias experimentales, etc. de un modo singular,

¿Por qué no reivindicamos aulas específicas para un desarrollo comportamental del aprendizaje y apropiación de las LEs, aulas que sirvan para experimentar la emoción del cambio comportamental que implica toda apropiación de una nueva lengua, aulas que resulten el umbral para una sociedad de la cultura?

$\mathrm{Y}$, en un sentido complementario,

¿Por qué no reivindicamos que en esos espacios-taller, presididos por las TICs y no tanto por nosotros mismos, no se enseñen lenguas extranjeras sino otros contenidos curriculares (incluidos los grandes temas transversales) que habrán de ser desarrollados (tal vez, y en función de cada nivel, sólo comprensivamente) en, al menos, dos lenguas extranjeras?

Las LEs, en el aula escolar, serán un umbral para una sociedad de la cultura cuando nos permitan ayudar, en el preclaro sentido imaginado por Umberto Eco (1993: 376-377) a la construcción de “...una comunidad de personas que puedan captar el espíritu, el perfume, la 
atmósfera de un habla distinta...". Y para ello es preciso, al margen de cualquier metodología didáctica, que el aula de LEs se dote con un discurso, con una conversación, con una emoción... donde la cultura presida toda acción de comunicación y aprendizaje. Maxine Greene (1986: 281) lo ha sintetizado, ya hace tiempo, al escribir que:

En una época de aumento creciente del lenguaje técnico, de fórmulas burocráticas, de juegos de simulación, y de una lengua franca que surge con fuerza de la sociedad mediática, puede que resulte cada vez más necesario para el profesorado imaginar un tipo de discurso y situaciones de habla en las que, y a través de las cuales, los alumnos puedan abrirse a sus mundos más sentidos, unos a otros, y también a sí mismos.

Claro que, previamente, también es preciso que, tanto el profesorado de LEs cuanto quienes en las universidades profesamos en DLE, hablemos y discutamos sobre todo ello y sus implicaciones. Porque a esto no se llega sin reivindicaciones ni sin consecuencias. Tampoco sin una perspectiva ciertamente utópica.

\section{Otra DLE es POSIBLe}

Igual que hay otra manera de imaginar la sociedad, a sabiendas de que otro mundo es posible, los didactas de LEs disponemos hoy de otras respuestas a lo que una lengua es y representa muy distintas a las que dábamos hace un par de décadas. Por lo que es fácil suponer que, de hoy para mañana, otra DLE es posible. Sin negar la dimensión comunicativa, que no es otra cosa que el aspecto más utilitarista y funcional del lenguaje, podemos pensar que las lenguas son el pensamiento -hecho voz o hecho letra-de nuestro comportamiento intercultural. Y en este contexto, como ya señalé más arriba, podemos imaginar el sentido de la apropiación de las LEs como un compromiso en la acción intercultural. Y su enseñanza y su aprendizaje, visto desde esta perspectiva, será una forma de acción educativa orientada a favorecer y alimentar el encuentro en el diálogo entre culturas diferentes. Y el resultado de este proceso de apropiación de varias LEs, como un comportamiento lingüístico distinto al habitual y más propio, será el de poder disponer de una competencia enriquecida para desarrollar nuestras interacciones interculturales en una cultura del mestizaje.

Una didáctica de LEs comprometida en esta dirección puede ser el umbral de penetración en esa cultura del mestizaje que algunos vislumbramos como aval de una sociedad de la cultura, al menos con mejores garantías que las ofrecidas por los patrones al uso. Claro que imaginar las LEs y la DLE como la antesala de esa sociedad de la utopía, a la que no llegaremos a rozar con nuestros dedos, pero hacia la que avanzamos en cada intento que hacemos por tocarla y sentirla, es un ejercicio más intelectual de lo que a simple vista parece. Acostumbrados a lo que parece que tiene que ser nuestro desarrollo profesional como educadores en LEs, los didactas de LEs nos hemos arrojado en brazos -de forma casi exclusiva- de las tareas de construcción de nuestro conocimiento didáctico del contenido y del conocimiento profesional didáctico. Y apenas percibimos el hecho de que en el mundo de las LEs, de hoy para mañana, hay un crecimiento que avanza al margen -y pesar- del desarrollo curricular en los sistemas formales de la educación escolar.

El lingüista, semiótico y ensayista búlgaro Tzvetan Todorov (2002), al final de su reciente 
libro Memoria del mal, tentación del bien, identifica -entre otras amenazas posibles para nuestro recién estrenado siglo XXI- el creciente peligro de la deriva instrumental: una amenaza que consiste en que los países democráticos estamos olvidando los fines para centrarnos en los medios. Un peligro -me temo- que puede afectar, también, a nuestra profesión de didactas de las LEs si seguimos concentrando toda nuestra atención en la arquitectura curricular de estas lenguas y dejamos de atender los fines que les son propios como un patrimonio cultural por excelencia.

Un ejercicio intelectual comprometido y serio nos puede llevar a pensar que, en otro plano distinto al de la simple racionalidad técnica de nuestra profesión (tantos y tantos saberes y procedimientos sobre planificación, gestión y evaluación en el aula de LEs), se encuentra una racionalidad crítica -en el sentido más próximo a la percepción de Habermas (1979). Una racionalidad que nos ayuda a contemplar la dimensión educativa y cultural de las LEs como algo más que lo que vemos, sentimos o padecemos tantas horas de nuestra vida. Una racionalidad que, desde un planteamiento ecológico-cultural, impulse un equilibrio armónico basado en la pluralidad lingüística y en la acción intercultural. Algo muy diferente de la tendencia conformista de las administraciones educativas que no acaban de afrontar el reto de la oferta simultánea de varias LEs desde la educación primaria, aún con competencias disociadas -que es una muy buena solución, como hace tiempo sabemos desde la investigación en DLE (cf. Vez, 1999, 2003). Pluralidad que, sin duda, satisface el ideal de quienes queremos estar unidos en la diversidad y de quienes entendemos el progreso bajo la ecuación de lenguas extranjeras (en plural) $=$ cultura.

Si el mundo del sistema educativo formal está enfermo (o en crisis, como algunos prefieren matizar), el de las LEs no lo está. Muy al contrario, resulta más vivo y entusiasta que nunca, a pesar de que en países como el nuestro se retroceda a favor de una orientación favorable hacia su estudio académico en forma de lenguas-asignatura. Si uno no puede comprender muy bien cómo se ha podido asesorar al gobierno de este país, en su reciente modificación de los currícula de educación secundaria -en la dirección (back to the basis!) de reforzar el conocimiento gramatical incluso en el primer ciclo de la ESO- podría pensar para su consuelo (como yo hago, al menos) que el gobierno tiene una poderosa razón para ello: las aulas actuales sólo sirven para explicar la lengua como objeto de conocimiento, y evaluar su apropiación efectiva como la asimilación en exclusiva de un conocimiento escrito. Y, por supuesto, a riesgo de perder las próximas elecciones, no están dispuestos a alterar su política presupuestaria de déficit cero, aumentado el gasto que supondría para la cartera de educación una fuerte inversión en aulas de LEs con dotaciones propias de TICs avanzadas, en formación de su personal docente, en políticas de submersión e inmersión cultural del alumnado y del profesorado, etc. Algo que, tal vez creen, no sería bien recibido por una sociedad de votantes que se contenta con lo que hay y, de no ser el caso, lo resuelve por medios alternativos... que también los hay (al menos para una gran minoría cualificada).

Permítaseme ampliar ahora algo más mi argumento: si el mundo del sistema educativo formal está enfermo, el de la educación en sistemas no formales, como es el de la educación de adultos en LEs, no lo está tanto. Ni lo está en igual medida el territorio formal de los ciclos formativos. Ni se consiente que daño alguno pueda afectar a su creciente desarrollo actual. Y a poco que pensemos, existen pocas dudas acerca del hecho de que las problemáticas que de hoy para mañana se van a plantear en el aprendizaje y la evaluación en (varias) LEs, en 
escenarios extraescolares y posteriores a la escolarización, no sólo requieren nuestra atención como expertos en DLE hoy, ahora mismo, sino que los resultados que se obtengan desde la investigación en estos campos, hasta ahora vírgenes para nuestra acción didáctica, serán de enorme influencia mañana en las terapias de curación de esas enfermedades (que no son endémicas) que afectan tan directamente a los aprendizajes y a la enseñanza de las LEs en el mundo escolar formal.

\section{Conclusión}

Lo hasta aquí expuesto tiene hondas raíces en una reflexión que si bien es de hoy para mañana, como en su propio título dejo constancia, ha sido construida en el transcurso del tiempo que va de ayer a hoy. No puedo estar más de acuerdo con la magnífica expresión que supo dar a esta misma idea Hannah Arendt cuando afirmaba que "el pasado no lleva hacia atrás sino que impulsa hacia delante y, en contra de lo que se podía esperar, es el futuro el que nos lleva hacia el pasado". Desde hace ya un tiempo, algunos colegas de DLE adscritos al Área de Conocimiento de Didáctica de la Lengua y la Literatura venimos sintiendo la necesidad de clarificar cuestiones relativas a un cierto desánimo y malestar profesional que están caracterizando a esta sub-área (¿?) de conocimiento científico con altas responsabilidades docentes e investigadoras en el conjunto de las universidades españolas. Una clarificación que pasa, en primera instancia, por afrontar cuestiones relativas a los objetos de la investigación en DLE desde, como aquí he tratado de descifrar, la construcción de nichos ecológicos que nos ayuden en la ardua tarea de institucionalizar y acotar nuestro territorio una vez lo hayamos sabido definir como tal. Sin duda, una cuestión que va a precisar de todo nuestro esfuerzo colaborativo en los años venideros.

No cabe duda que la presente situación en el territorio universitario internacional, igual que en el de las universidades españolas, ha disparado las alarmas que advierten de la necesidad de extremar las precauciones acerca de una mayor y más exquisita investigación de calidad en todos los territorios científicos. Como todas los demás, nuestro ámbito específico de la DLE tendrá que sobrevivir en los nuevos mundos del crecimiento científico y superar los retos de los nuevos patrones de estima, calidad y pertinencia que se imponen en esos mundos. Tenemos una importante experiencia ya construida en estos avatares: a lo largo de décadas y décadas, la DLE -como enseñanza y aprendizaje de idiomas- ha cumplido en este país de modo muy satisfactorio los diversos objetivos que le eran propios. Y, sin duda, el mundo de la educación escolar así lo ha apreciado. Claro que, hoy en día, ni nuestro foco de atención -como referente para otras formas de hacer didáctica en LEs- puede restringirse en exclusiva al territorio escolar, ni tiene ya sentido identificarlo como "enseñanza y aprendizaje de...". Planteado como un ámbito de formación en educación para la pluralidad lingüística y la acción intercultural, la DLE ha abierto nuevos horizontes de investigación que progresivamente, y por fuerza, han de repercutir en el alcance de otros planteamientos en la docencia universitaria, al tiempo que en otros marcos de formación en este ámbito, que van más allá de los títulos generalistas de Grado que se avecinan.

Desde una concepción de profesionales de la DLE que comprenden, investigan y toman decisiones sobre la actividad plural de la formación en educación en la pluralidad lingüística y en la acción intercultural, las iniciativas que surjan de todos los que profesamos en este 
territorio son las que pueden aprovecharse de un modo más económico y rápido. Y, actualmente, el caudal de tales iniciativas es bastante rico. Por eso, a modo de conclusión, dejo aquí una serie de opiniones (en orden intencionadamente aleatorio y no prelatorio) que pueden alimentar nuestro debate en la construcción de nuestra DLE del hoy para el mañana:

- Que la estrategia más adecuada para avanzar en el dominio de la investigación en DLE es la de promocionar, favorecer, estimular, apoyar y difundir las iniciativas particulares que surgen de sus propios profesionales, de grupos de trabajo y de los departamentos universitarios. Crear el clima y las condiciones para que esas iniciativas respondan a señas de identidad propias de la DLE y no de otros ámbitos resulta, a todas luces, un objetivo ineludible. Pero, tal vez, la primera tarea a afrontar, con la seguridad de que va a ser mucho más fructífera que cualquier iniciativa surgida institucionalmente y con visos de normatividad, sea la de discutir y consensuar cuáles pueden ser los frentes de actuación y los planteamientos metodológicos que doten de rigor y pertinencia a la investigación en DLE.

- Que la DLE no es, por ser didáctica, el ámbito de interés exclusivo de los problemas educativos de las LEs en el territorio escolar formal. Que otros ámbitos formales poco y mal aceptados (de ayer a hoy) por la DLE, como son la formación profesional y los aprendizajes y enseñanzas en las Escuelas Oficiales de Idiomas de este país, son de especial relevancia para nuestro desarrollo de hoy para mañana. En igual o en mayor medida, lo son también los aprendizajes de varias LEs por parte de adultos que poseen este tipo de necesidades sentidas en el actual entramado de las profesiones, propio de la postmodernidad que vivimos y, en especial, como resultado de los crecientes modelos de inserción en el tejido laboral bajo los parámetros de la movilidad transnacional europea.

- Que el Marco de Referencia Europeo para el aprendizaje, la enseñanza y la evaluación de lenguas es también nuestro marco de referencia inmediato en DLE, lo mismo que los son todos y cada uno de los instrumentos que le sirven hoy de desarrollo y que, mañana, pueden llegar a incorporar los que nosotros mismo hayamos elaborado como resultado de nuestra atención colaborativa a este frente de crecimiento.

- Que no es posible llegar al punto de reconocimiento institucional de la DLE, que de ayer a hoy todos hemos tratado de alcanzar, sin un esfuerzo de hoy para mañana en la dirección del trabajo en red. Si el modelo de la investigación en equipo puede ser un paso inicial para muchos que vienen trabajando de siempre en este ámbito desde su propio esfuerzo individual, el aprender a emprender tareas en red -en grandes redes nacionales e internacionales- marca una ruta a la que no podemos dar la espalda. El asociacionismo especializado, y me consta que estamos dando ya pasos importantes en ello, si se desarrolla como plataforma colaborativa de intereses en DLE y no de otros intereses (para los que ya existen, por cierto, otras formas de organización en el ámbito de las LEs), puede servir de ayuda para este propósito.

- Que el multilingüismo en Europa es hoy una realidad que nos permite observar un hecho singular sin precedentes: Las comunidades lingüísticas europeas se aproximan cada vez más entre sí, por lo que los conocimientos superficiales sobre la variedad de lenguas europeas han dado paso a un tipo de contacto concreto con un número cada vez mayor de nacionales europeos hablantes de otras lenguas. La realidad de 
mañana puede muy bien ser -por razones de eficacia, de desarrollo sostenible, de cultura y de política lingüística en la Unión- la de una intercomprensión paneuropea, a través del ejercicio de la práctica continuada de la 'comunicación en tándem' que permita a un europeo culto entender directamente a otros europeos (de diferentes lenguas y culturas) que hablen en sus propias lenguas, y pueda continuar hablando con ellos en su propia lengua materna si los interlocutores -por su parte- han adquirido una competencia receptiva en la lengua que él habla y escribe. La DLE tiene una de sus asignaturas pendientes en la potenciación de estudios sobre intercomprensión lingüística y cultural en la dimensión europea (Vez, 2003) y, al igual que en otras cuestiones no superadas, experimenta un considerable retraso en la incorporación de este planteamiento como uno de sus objetos de investigación.

- Que las TICs deben ocupar un centro de interés en la investigación en DLE en la medida en que las aulas de lenguas extranjeras serán, de hoy para mañana, lo que Kroonenberg $(1994 / 1995)$ y Warschauer $(1995,1997)$ han denominado "electronic classrooms", donde las conexiones on-line y el empleo de cualquier otro tipo de recurso informático formarán parte habitual de las tareas de aprendizaje.

- Que la colaboración, de ayer a hoy, en diferentes aspectos de la DLE entre colegas del área (aún vigente) de DLL y de otras áreas de conocimiento sigue siendo deseable. Ahora bien, de hoy para mañana, y en virtud de los resultados de la nueva catalogación de áreas de conocimiento en el sistema universitario de nuestro país, seguirá siendo necesaria, pertinente y rigurosa en función de la construcción de acuerdos institucionales (y no personales), ya sean tácitos o explícitos, relativos a la definición de su ámbito, a su proyección en la docencia y en la investigación, a un reconocimiento exactamente equiparable al de cualquier otro ámbito del catálogo de referencia, y a la reciprocidad de funciones, categorías, estima, reconocimiento, etc. en el desarrollo personal y profesional del personal adscrito a unas y otras áreas. Una situación que hoy no es recíproca, en la medida en que sólo funciona en el caso de la buena apreciación que desde la DLE se produce hacia colegas de áreas filológicas, etc. (participación en tribunales de tesis, concursos a plazas, grupos de investigación, publicaciones, etc.) pero que no encuentra parangón en la nula o escasa apreciación (salvando casos singulares que, personalmente, atribuyo a circunstancias donde se impone la mediación de la amistad) que observamos en la dirección contraria.

- Que la DLE no puede seguir formando parte del área de conocimiento denominada hoy DLL. Al margen de lo que la nueva catalogación universitaria pueda dar de sí, se hace necesario que - de hoy para mañana- se tenga en cuenta, en el territorio institucional, nuestro ámbito de especificidad y crecimiento.

Permítaseme, por último, agradecer la confianza que los editores de Porta Linguarum han depositado en mi persona a la hora de solicitar mi colaboración en este primer número que alumbra, si duda, el nacimiento de una prometedora singladura y de un avance decisivo por el trasfondo de las cuestiones que aquí he tratado. Como dice mi paisano Manolo Rivas, de nosotros ...se espera a veces demasiado, como de aquel ingenioso Jackob que transformaba los gramos de noticias en toneladas de esperanza. Es comprensible la tensión ante semejante demanda. Pero, iqué suerte que esperen de uno algo! 


\section{REFERENCIAS}

Armán Lomba, L. (2003). Competencia Comunicativa Oral en Francés- $L_{2}$ : Logros del alumnado al finalizar la ESO. Vigo: Universidad de Vigo (tesis doctoral en microficha).

Candlin, C. (ed.) (1981). The Communicative Teaching of English: Principles and an Exercise Typology. London: Longman.

Coyle, Y., Verdú, M. y Valcárcel, M. (2002). Teaching English to Children -Interactivity and Teaching Strategies in the Primary FL Classroom. Frankfurt: Peter Lang.

Eco. U. (1993). La ricerca della lingua perfetta nella cultura europea. Roma-Bari: Laterza.

Edelhoff, C. (1980). "Kommunicative Lernziele im Fremdsprachenunterricht: Vom Verstehen zum Aubern", en Sprache und Beruf, 2: 61-74.

Ellis, R. (1990). Instructed second language acquisition. Oxford: Blackwell.

Ellis, R. (1994). The study of second language acquisition. Oxford: O. U. P.

Ellis, R. (1995). "Appraising second language acquisition theory in relation to language pedagogy", en G. Cook y B. Seidlhofer (eds.), Principles and practice in applied linguistics: Studies in honor of H. G. Widdowson. Oxford: O. U. P., 73-90.

Ellis, R. (Ed.). (1987). Second language acquisition in context. Englewood Cliffs, N. J.: PrenticeHall.

Galisson, R. (1980). D’hier à aujourd'hui la didactique générale des langues étrangères. Du structuralisme au fonctionnalisme. Paris: Clé International.

Greene, M. (1986). "Philosophy and teaching", en M. C. Wittrock (ed.), Handbook of research on teaching. Nueva York: Macmillan, 279-501.

Habermas. J. (1979). Communication and the Evolution of Society. London: Heinemann.

Hymes, D. (1972). “On communicative competence”, en J. Pride y J. Holmes (eds.), Sociolinguistics. Harmondsworth, Mddx., Penguin Books, 269-293.

Hymes, D. (1974). Foundations in Sociolinguistics: An Ethnographic Approach. Philadelphia: Philadelphia University Press.

Instituto Cervantes (2002). Marco de referencia europeo para el aprendizaje, la enseñanza y la evaluación de lenguas. Alcalá de Henares: Instituto Cervantes (http://cvc.cervantes.es/obref/ marco)

Kramsch, C. (ed.) (1995). Redefining the boundaries of language study. Boston: Heinle.

Kroonenberg, N. (1994/1995). "Developing communicative and thinking skills via electronic mail", en TESOL Journal, 24-27.

Moravsky, J. M. (1990). Thought and Language. London: Routledge.

Pennycook, A. (2001). Critical Applied Linguistics: a critical introduction. London: LEA.

Peñate Cabrera, M. (coord.) (1998). Evaluación de la Enseñanza del Inglés. Educación Primaria. Las Palmas de Gran Canaria: Instituto Canario de Evaluación y Calidad Educativa.

Phillipson, R. (1992). Linguistic Imperialism. Oxford: Oxford University Press.

Phillipson, R. (2001). English-only Europe? Language policy challenges. London: Routledge.

Savater, F. (1997). El valor de educar. Madrid: Ariel.

Saville-Troike, M. (1989). The Ethnography of communication: An introduction. Oxford: Basil Blackwell.

Schön, D. (1992). La formación de profesionales reflexivos. Barcelona: Paidós-M.E.C.

Spolsky, B. (1990). "Introduction to a colloquium: The scope and form of a theory of second language learning", en TESOL Quarterly, 24: 609-616.

Stern, H. H. (1983). Fundamental concepts of language teaching. London: Oxford University Press. 
Toulmin, S. (1977). La comprensión humana. El uso colectivo y la evolución de los conceptos. Madrid: Alianza (La publicación original es de 1972).

Vez, J. M. (1999). "As aprendizaxes de linguas estranxeiras. Avances da investigación no marco dunha dimensión europea", en Revista Galega do Ensino (Xunta de Galicia), 23: 115-145.

Vez, J. M. (2000). Fundamentos lingüísticos en la enseñanza de lenguas extranjeras. Barcelona: Ariel.

Vez, J. M. (2001a). "Repensar la formación de maestros en DLL para la cultura de la profesionalización.”, en F. J. Perales et al. (eds.), Las Didácticas de las Áreas Curriculares en el siglo XX. Granada: GEU: 149-176.

Vez, J. M. (2001b). Formación en didáctica de las lenguas extranjeras. Rosario (Argentina): Homo Sapiens.

Vez, J. M. (2002a). "Introducing a European dimension into EFL teacher education", en J. M. Vez (ed), The Teaching of English as a Foreign Language: A European Perspective (CAUCE, 25 Special Issue). Sevilla: Universidad de Sevilla, 147-163.

Vez, J. M. (2002b). "El aula de lenguas extranjeras: umbral para una sociedad de la cultura", en AULA de Innovación Educativa, 117: 6-12.

Vez, J. M. (2002c). "De la lingüística del contraste a la didáctica de la integración en las aulas de lengua extranjera. Un punto de vista crítico", en Carabela, 51: 5-25.

Vez, J. M. (2003). "La dimensión intercomprensiva en el aprendizaje de lenguas extranjeras en Europa", en CAUCE, 26, (en prensa).

Vez, J. M. (ed.) (2002). Didáctica de la lengua extranjera en educación infantil y primaria. Madrid: Síntesis.

Vez, J. M. y Martínez, E. (eds.) (2002). Competencia Comunicativa Oral en Lenguas Extranjeras. Investigación sobre logros del alumnado gallego de Inglés y Francés al finalizar la ESO. Santiago de Compostela: ICE-Servicio de Publicaciones de la USC.

Warschauer, M. (1997). "Computer-mediated collaborative learning: Theory and practice", en The Modern Language Journal, 81: 470-481.

Warschauer, M. (ed.) (1995). Virtual connections: Online activities and projects for networking language teachers. Honolulu: University of Hawaii.

Williams, M y Burden, R. (1997). Psychology for Language Teachers: a Social Constructivist Approach. Cambridge: C.U.P. 